\title{
Solvent-free, visible-light photocatalytic alcohol oxidations applying an organic photocatalyst
}

\author{
Martin Obst and Burkhard König*
}

\author{
Full Research Paper \\ Address: \\ Institute of Organic Chemistry, University of Regensburg, \\ Universitätsstraße 31, 93040 Regensburg, Germany \\ Email: \\ Burkhard König ${ }^{*}$ - burkhard.koenig@chemie.uni-regenburg.de \\ * Corresponding author \\ Keywords: \\ benzylic alcohol; oxidation; photocatalysis; solvent free; visible light
}

Beilstein J. Org. Chem. 2016, 12, 2358-2363.

doi:10.3762/bjoc. 12.229

Received: 01 September 2016

Accepted: 27 October 2016

Published: 09 November 2016

Associate Editor: C. Stephenson

(c) 2016 Obst and König; licensee Beilstein-Institut.

License and terms: see end of document.

\begin{abstract}
A method for the solvent-free photocatalytic conversion of solid and liquid substrates was developed, using a novel rod mill apparatus. In this setup, thin liquid films are realized which is crucial for an effective photocatalytic conversion due to the low penetration depth of light in heterogeneous systems. Several benzylic alcohols were oxidized with riboflavin tetraacetate as photocatalyst under blue light irradiation of the reaction mixture. The corresponding carbonyl compounds were obtained in moderate to good yields.
\end{abstract}

\section{Introduction}

According to a classification made by Wilhelm Ostwald, one of the pioneers in the field of physical chemistry and Nobel Prize laureate 1909 , chemistry can be divided into the four sub-disciplines thermochemistry, electrochemistry, photochemistry, and mechanochemistry, depending on the kind of energy involved in a chemical process [1]. Among these, mechanochemistry is nowadays a well-established method for the solvent-free conversion of solid reactants. The reaction is driven by mechanical energy, which is for instance realized by grinding in ball mills or pestle and mortar. Obviously, this method possesses several advantages compared to reactions, which are performed in solution: toxic solvents and wastes are avoided, making the process more environmentally friendly and sustainable. Furthermore, quantitative yields can be achieved, avoiding work-up and laborious purification [2]. Moreover, solubility problems, like insolubility of one reactant or the different polarity of two reactants, are solved. Examples for mechanochemical syntheses include stoichiometric reactions such as the Knoevenagel condensation and the Wittig reaction, but also reactions catalyzed by metal catalysts, like the Sonogashira coupling and the Suzuki coupling [1].

Photocatalysis, as a part of Ostwald's sub-discipline photochemistry, is a rather new field of great academic interest. 
Namely, visible-light photocatalysis applying an organic, redoxactive catalyst allows mild and efficient transformations. By exciting the photocatalyst, which then exchanges electrons with the substrate, light energy is converted into chemical energy [3] This approach avoids expensive reagents and harsh reaction conditions, which are improvements compared to conventional processes. Considering that, we envisaged combining photocatalysis with mechanochemistry, thereby making use of the advantages of both disciplines. In such an approach, solid substrates would be grinded under visible light irradiation. In contrast to mechanochemistry, the process would be driven by light energy and not by mechanical energy, but profit from the absence of toxic solvents, high concentrations of the substrate, and easy work-up. Furthermore, undesired effects of the solvent like hydrogen-atom transfer or the formation of byproducts could be excluded.

For liquid substrates, some examples for photocatalytic, solvent-free conversions are reported, such as the oxidation of benzyl alcohol to benzaldehyde [4] and the oxidation of benzenes to phenols [5]. Another field of solvent-free photocatalysis is the application of heterogeneous, semiconducting photocatalysts, often based on titanium dioxide and other metal oxides [6-8]. However, to the best of our knowledge, no solvent-free visible-light driven transformation of a solid substrate applying an organic photocatalyst has been reported yet.

In this work, we present a novel milling apparatus, which we developed especially for the conversion of solid substrates. Applying this apparatus, the solvent-free oxidation of various benzylic alcohols to their corresponding carbonyl compounds using riboflavin tetraacetate as photocatalyst under blue light irradiation was performed. Furthermore, the oxidation of a liquid benzylic alcohol is presented as well.

\section{Results and Discussion}

For our investigations on solvent-free photocatalytic conversions, we chose riboflavin tetraacetate (RFTA) as photocatalyst. RFTA and flavin derivatives in general are well-known bluelight absorbing photocatalysts, which can oxidize a variety of substrates under aerobic conditions with oxygen as terminal oxidant. Flavins were studied extensively for the oxidation of alcohols, amines, methylbenzenes, styrenes, and phenylacetic acids [9-12]. Some derivatives were also immobilized on silica gel and applied in the oxidation of benzyl alcohols [13] Furthermore, it was shown that the oxidation power of RFTA can be increased by coordination to scandium triflate [14] Recently, the $E / Z$-isomerization of olefins with riboflavin as catalyst was reported [15], which was also used for cyclization to form coumarins [16].
In this work, we focus on benzylic alcohols as substrates since their oxidation to the corresponding carbonyl compounds can be simply performed in acetonitrile/water mixtures. Thus, they are suitable model substrates for the investigation of our solventfree principle.

In mechanochemistry, reactions are performed by grinding the reaction mixture in ball mills, such as the vibrational ball mill or the planetary ball mill, or with a pestle and mortar. In preliminary studies, we tested a vibrational ball mill for photocatalytic oxidations with riboflavin tetraacetate, using a transparent milling chamber. However, this reactor proved to be unsuitable: the solid reaction mixture prevented light to reach the photocatalyst, both by attachment of small amounts of solid to the inner side and shielding within the milling chamber. The low penetration depth of light led us to the conclusion that thin interfaces of reactants, combined with continuous grinding, are necessary. Based on these considerations, we constructed a rod mill, consisting of a test tube which contains the reaction mixture, a glass rod, which is fixed to a stirrer, and an LED frame with 5 LEDs $(\lambda=455 \mathrm{~nm})$. Figure 1 shows a schematic representation and photographs. Before reaction, the solid substrate and photocatalyst are gently homogenized with a spatula, followed by grinding with pestle and mortar. The reaction mixture is then filled into the test tube. Subsequently, the rotating glass rod is pressed into the test tube, which leads to vertical migration of the reaction mixture and the formation of a film between the inner wall of the test tube and the glass rod. The reaction is carried out by rotation and irradiation with the LEDs from the outside.

We started our investigations with the oxidation of 4,4'dimethoxybenzhydrol (1a) to 4,4'-dimethoxybenzophenone (1b), applying 10\% RFTA (Scheme 1).

In this initial trial, the product could be obtained in $72 \%$ yield. Subsequently, we varied the amount of RFTA (Table 1).

Lowering the catalyst concentration from $10 \%$ to $5 \%$ does not significantly influence the yield (entry 2, Table 1, yield in average of four trials). Even a further decrease to $2 \%$ (entry 3 , Table 1) causes no essential decline. However, at a RFTA concentration of $1 \%$ (entry 4 , Table 1 ), the isolated yield was only $61 \%$; very low catalyst concentrations are problematic due to inactivation of a certain portion of the catalyst, which might be due to burning.

No product was formed in the dark (entry 5, Table 1) and only traces were obtained without photocatalyst (entry 6, Table 1). However, in this control reaction, melting of the substrate was observed. All reaction mixtures containing RFTA appeared 


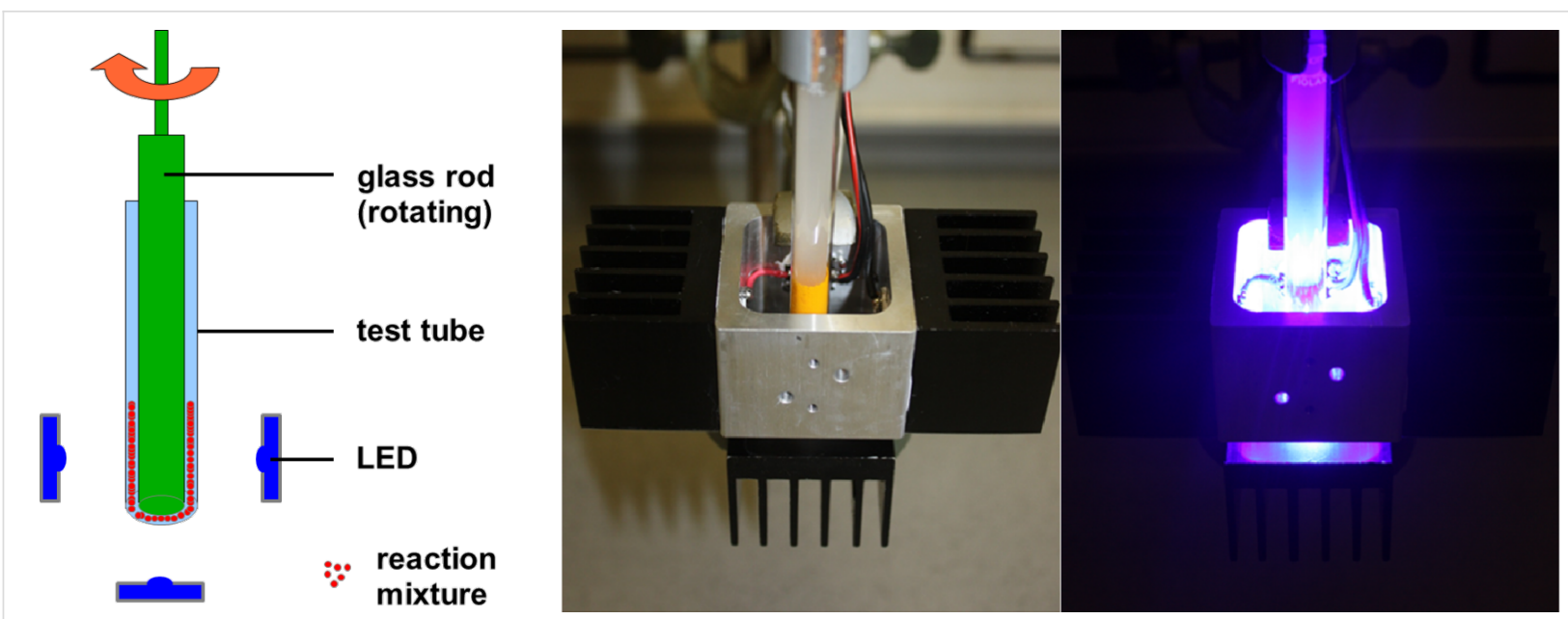

Figure 1: Rod mill, schematic (left) and photographs (middle and right).

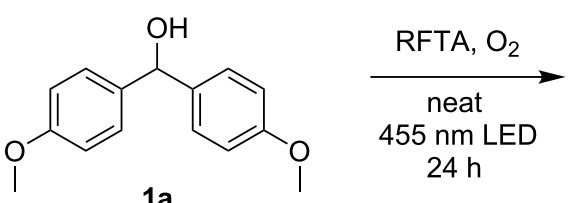

1a

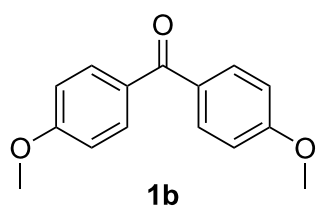

$1 \mathrm{~b}$

Scheme 1: Oxidation of 4,4'-dimethoxybenzhydrol (1a) to 4,4'-dimethoxybenzophenone (1b).

\begin{tabular}{|c|c|c|}
\hline Entry & RFTA (\%) & Yield (\%) \\
\hline 1 & 10 & 72 \\
\hline 2 & 5 & 74 \\
\hline 3 & 2 & 69 \\
\hline 4 & 1 & 61 \\
\hline $5^{a}$ & 10 & 0 \\
\hline 6 & - & traces \\
\hline $7^{b}$ & 5 & traces \\
\hline $8^{c}$ & 5 & traces \\
\hline $9^{d}$ & 5 & 78 \\
\hline
\end{tabular}

aln the dark; ${ }^{b}$ in the dark at $85^{\circ} \mathrm{C}$; ${ }^{c}$ with cooling; ${ }^{d}$ no rotation.

solid. The fact that the substrate was molten without RFTA leads to the conclusion that the blue light irradiation was heating the substrate and temperatures higher than its melting point $\left(67-70{ }^{\circ} \mathrm{C}\right)$ occurred. The temperatures of the reaction mixtures were measured using an IR thermometer. Though, values not higher than $42{ }^{\circ} \mathrm{C}$ were obtained. This could be explained by the fact that the IR thermometer records only the surface temperature of the test tube; the temperature within the reaction mixture might be above this value. When the reaction mixture was heated to $85^{\circ} \mathrm{C}$ in the dark, melting was observed (entry 7, Table 1) and only traces of product were formed, showing that the oxidation of the substrate is not only due to heating. For further investigation, the reaction was performed within a continuous water cooling (entry 8 , Table 1 ). In this setup, no product was formed. Therefore, the heating effect of the blue light was found to be necessary to perform the reaction: melting of the substrate leads to mobility of the substrate and catalyst molecules, ensuring the occurrence of the catalytic cycle. When the rotation was switched off after the formation of the solid film ( $2 \mathrm{~min}$ ), followed by LED irradiation (entry 9 , Table 1), the product was obtained in similar yield compared to the reactions performed under grinding (entry 2, Table 1), indicating that the grinding does not contribute to the essential heating. Hence, light irradiation fulfils a double function: the excitation of the photocatalyst and melting of the substrate, inducing mobility of the molecules. As mentioned above, the reaction mixtures containing RFTA appeared solid. Possibly, small droplets of molten substrate were formed; due to the presence of RFTA, no homogeneous liquid phase was observed. In mechanochemistry, the formation of hot spots by friction heating with high local temperatures and the existence of liquid eutectic states are believed to be responsible for chemical transformations [1]. In contrast, in our rod mill apparatus, heating is not induced by mechanical but by electromagnetic energy input, realized by blue light irradiation. Furthermore, the heat input is not the primary cause for the reaction, but its prerequisite. 
Subsequently, the scope of the benzylic alcohol oxidation was investigated, applying 5\% of RFTA. Four solid alcohols were oxidized to their corresponding ketones or aldehydes, including fluorenol (9-hydroxyfluoren), benzhydrol, benzilic acid, and 3,4,5-triethoxybenzyl alcohol (2a-5a). Scheme 2 shows the products and isolated yields, which are in the range from $37 \%$ to $72 \%$. In contrast to 4,4 '-dimethoxybenzhydrol, a liquid paste was observed in all cases, indicating melting of the substrate or the product, which maintains mobility. The oxidation of benzilic acid and benzhydrol was also performed using an LED setup containing only 4 LEDs instead of 5 LEDs like in the frame rod mill. Here, the obtained yields were significantly lower (36\% and $30 \%$ vs $55 \%$ and $50 \%$ ). This shows that the amount of energy reaching the reaction mixture plays a crucial role.

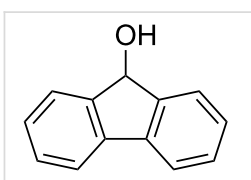

$2 a$

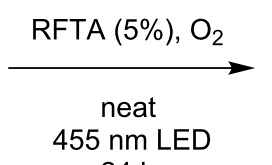

$24 \mathrm{~h}$

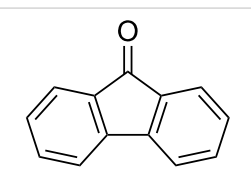

2b $(72 \%)$<smiles>OC(c1ccccc1)c1ccccc1</smiles>

3a

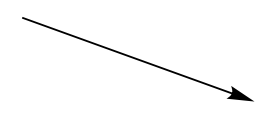<smiles>O=C(O)C(O)(c1ccccc1)c1ccccc1</smiles>

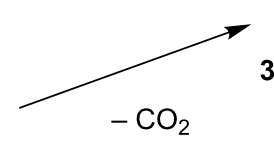

3b $(50 \%, 3 a ; 55 \%, 4 a)$

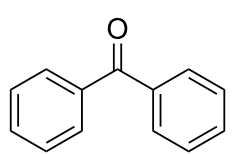

$4 a$

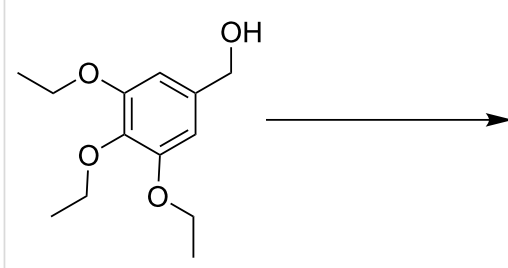

$5 \mathbf{a}$

Scheme 2: Scope for benzylic alcohol oxidation and obtained yields.

Furthermore, the suitability of the rod mill for the conversion of liquid substrates was tested. 4-Methoxyphenyl methyl carbinol was oxidized applying $5 \%$ of RFTA (Scheme 3 ).

The crude ${ }^{1} \mathrm{H}$ NMR spectrum recorded after the reaction shows a quantitative conversion of the staring material and no visible<smiles>COc1ccc(C(C)O)cc1</smiles>

$6 a$

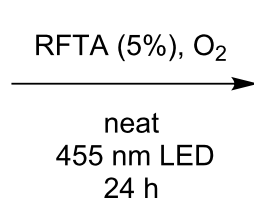

$24 \mathrm{~h}$<smiles>COc1ccc(C(C)=O)cc1</smiles>

6b $(64 \%)$
Scheme 3: Oxidation of 4-methoxyphenyl methyl carbinol (6a) to 4-methoxyacetophenone $(6 b)$

side product formation (see Experimental). In general terms, this shows the potential of the method for an efficient synthesis with direct product formation, facilitating work-up. However, the isolated yield was only $64 \%$ (average of two trials), indicating loss in the column purification process and decomposition of a part of the product in the reaction mixture.

\section{Conclusion}

We have developed a method for the solvent-free photocatalytic conversion of solid and liquid substrates using a novel rod mill apparatus. The applicability of the rod mill was shown for the oxidation of benzylic alcohols with riboflavin tetraacetate as photocatalyst under blue light irradiation; the products were isolated in moderate to good yields. In case of the solid benzyl alcohols, the reactions were found to proceed via the molten state of the substrates or products, which enables mobility of the substrate and catalyst molecules and the occurrence of the catalytic cycle. Thus, light fulfils the double function of both the excitation of the photocatalyst and heating of the reaction mixture.

To summarize, the new combination of photocatalysis and mechanochemistry, realized in a simple rod mill apparatus is an alternative to conventional reaction setups. It may provide advantages for the conversion of starting materials or catalysts with no or low solubility in the same solvent and reactions benefitting from high substrate concentrations.

\section{Experimental \\ Materials and methods}

NMR spectra were recorded on a Bruker Avance 300. 4,4'-Dimethoxybenzhydrol was purchased from Alfa Aesar, 9-hydroxyfluoren, benzhydrol, and 3,4,5-triethoxybenzaldehyde from Sigma-Aldrich, benzilic acid from Merck Schuchardt and 4-methoxyphenyl methyl carbinol from Fluorochem. Riboflavin tetraacetate was synthesized from riboflavin (Acros Organics) according to a procedure reported in the literature [17].

Technical data of the rod mill apparatus: 4 LEDs (455 nm, $700 \mathrm{~mA}$ ) on a square aluminium frame (inner diameter $35 \mathrm{~mm}$ ) and one LED below the test tube were used. The distance of 
each LED to the test tube was $10 \mathrm{~mm}$. The diameter of the glass rod was $8 \mathrm{~mm}$ and the inner diameter of the test tube was $9 \mathrm{~mm}$.

\section{Synthesis}

General procedure: The substrate and riboflavin tetraacetate were weighed into a mortar in stoichiometric amounts and gently homogenized with a spatula, followed by grinding with a pestle and mortar. The reaction mixture was filled into the rod mill test tube and the mass was determined. Subsequently, the rotating glass rod was pressed into the test tube, forming a film between the test tube and the glass rod. The reaction was carried out by rotation of the glass rod $(80 \mathrm{rpm})$ and parallel irradiation with the $455 \mathrm{~nm}$ LEDs for 24 hours. After the reaction, the product was isolated by flash column chromatography (gradient of ethyl acetate in petroleum ether).

\section{4,4'-Dimethoxybenzophenone (1 b)}<smiles>COc1ccc(C(=O)c2ccc(OC)cc2)cc1</smiles>

${ }^{1} \mathrm{H}$ NMR (300 MHz, $\left.\mathrm{CDCl}_{3}\right) 7.79(\mathrm{~m}, 4 \mathrm{H}, \mathrm{CH}), 6.96(\mathrm{~m}, 4 \mathrm{H}$, $\mathrm{CH}), 3.88\left(\mathrm{~s}, 6 \mathrm{H}, \mathrm{CH}_{3}\right)$; EIMS $m / z: 242.0924[\mathrm{M}]^{+}$.

\section{9-Fluorenone (2b)}

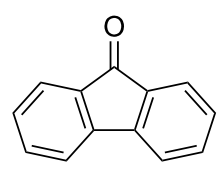

9-Hydroxyfluorene (82.0 mg, $0.45 \mathrm{mmol})$ and RFTA (12.3 $\mathrm{mg}$, $0.023 \mathrm{mmol}$ ) were weighed and $70.6 \mathrm{mg}$ of the mixture was used for reaction. Yield: $72 \% .{ }^{1} \mathrm{H}$ NMR $\left(300 \mathrm{MHz}, \mathrm{CDCl}_{3}\right)$ $7.66(\mathrm{~d}, 2 \mathrm{H}, \mathrm{CH}), 7.54-7.47(\mathrm{~m}, 4 \mathrm{H}, \mathrm{CH}), 7.30(\mathrm{~m}, 2 \mathrm{H}, \mathrm{CH})$; EIMS $m / z: 180.0579\left[\mathrm{M}^{+}\right.$.

\section{Benzophenone (3b)}<smiles>O=C(c1ccccc1)c1ccccc1</smiles>

3b from 3a: Diphenylmethanol $(73.3 \mathrm{mg}, 0.40 \mathrm{mmol})$ and RFTA $(10.9 \mathrm{mg}, 0.020 \mathrm{mmol}$ ) were weighed and $74.0 \mathrm{mg}$ of the mixture was used for reaction. Yield: $50 \%$. ${ }^{1} \mathrm{H}$ NMR $\left(300 \mathrm{MHz}, \mathrm{CDCl}_{3}\right) 7.83-7.79(\mathrm{~m}, 2 \mathrm{H}, \mathrm{CH}), 7.62-7.57$ $(\mathrm{m}, 2 \mathrm{H}, \mathrm{CH}), 7.51-7.46(\mathrm{~m}, 4 \mathrm{H}, \mathrm{CH})$; EIMS $m / z: 182.0730$ $[\mathrm{M}]^{+}$.

3b from 4a: Benzylic acid $(91.3 \mathrm{mg}, 0.40 \mathrm{mmol})$ and RFTA (10.9 mg, $0.020 \mathrm{mmol}$ ) were weighed and $89.2 \mathrm{mg}$ of the mixture was used for reaction. Yield: $55 \%$.

\section{3,4,5-Triethoxybenzaldehyde (5b)}<smiles>CCOc1cc(C=O)cc(OCC)c1OCC</smiles>

3,4,5-Triethoxybenzyl alcohol ( $96.1 \mathrm{mg}, 0.40 \mathrm{mmol}$ ) and RFTA (10.9 mg, $0.020 \mathrm{mmol}$ ) were weighed and $82.3 \mathrm{mg}$ of the mixture was used for reaction. Yield: $37 \%$. ${ }^{1} \mathrm{H}$ NMR $(300 \mathrm{MHz}$, $\left.\mathrm{CDCl}_{3}\right) 9.82$ (s, 1H, CHO), $7.08(\mathrm{~s}, 1 \mathrm{H}, \mathrm{CH}), 4.17-4.09$ (m, 6H, $\left.\mathrm{CH}_{2}\right), 1.45$ (t, 6H, $\left.\mathrm{CH}_{3}\right), 1.36\left(\mathrm{t}, 3 \mathrm{H}, \mathrm{CH}_{3}\right)$.

\begin{tabular}{|c|c|c|c|c|c|}
\hline \multirow[t]{2}{*}{ Entry ${ }^{a}$} & \multicolumn{2}{|c|}{ Amount, weighed $(\mathrm{mg} / \mathrm{mmol})$} & \multirow[t]{2}{*}{ (trial) } & \multirow[t]{2}{*}{ Total mass for reaction $(\mathrm{mg})$} & \multirow[t]{2}{*}{ Yield (\%) } \\
\hline & $1 a$ & RFTA & & & \\
\hline 1 & $85.5 / 0.35$ & $19.1 / 0.035$ & - & 77.2 & 72 \\
\hline \multirow[t]{4}{*}{2} & $85.5 / 0.35$ & $9.5 / 0.018$ & 1 & 76.7 & 70 \\
\hline & & & 2 & 76.3 & 79 \\
\hline & & & 3 & 81.4 & 70 \\
\hline & & & 4 & 83.2 & 76 \\
\hline 3 & $97.7 / 0.4$ & $4.4 / 0.008$ & - & 83.5 & 69 \\
\hline 4 & $97.7 / 0.4$ & $2.2 / 0.004$ & - & 76.6 & 61 \\
\hline 9 & $85.5 / 0.35$ & $9.5 / 0.018$ & - & 81.9 & 78 \\
\hline
\end{tabular}

an Table 1. 


\section{4-Methoxyacetophenone (6b)}<smiles>COc1ccc(C(C)=O)cc1</smiles>

Riboflavin tetraacetate was grinded with pestle and mortar before use. 4-Methoxyphenyl methyl carbinol and riboflavin tetraacetate were weighed into the rod mill test tube and the mixture was sonicated for $1 \mathrm{~min}$. The rotating glass rod was pressed into the test tube, forming a film between the test tube and the glass rod. The reaction was carried out by rotation of the glass rod $(80 \mathrm{rpm})$ and parallel irradiation with the $455 \mathrm{~nm}$ LEDs for 24 hours. After the reaction, the product was isolated by flash column chromatography (gradient of ethyl acetate in petroleum ether). Trial 1: 4-Methoxyphenyl methyl carbinol (82.2 $\mathrm{mg}, 0.54 \mathrm{mmol})$ and RFTA (14.0 mg, $0.03 \mathrm{mmol})$ were used. Yield: $63 \%$. Trial 2: 4-Methoxyphenyl methyl carbinol (178.5 mg, $1.17 \mathrm{mmol})$ and RFTA (31.9 mg, $0.06 \mathrm{mmol})$ were used. Yield: $65 \% .{ }^{1} \mathrm{H}$ NMR (300 MHz, $\mathrm{CDCl}_{3}$, Figure 2) 7.94 $(\mathrm{m}, 2 \mathrm{H}, \mathrm{CH}), 6.93(\mathrm{~m}, 2 \mathrm{H}, \mathrm{CH}), 3.87\left(\mathrm{~s}, 3 \mathrm{H}, \mathrm{OCH}_{3}\right), 2.55(\mathrm{~s}$ $\left.3 \mathrm{H}, \mathrm{CH}_{3}\right)$; CIMS: $151.0771[\mathrm{M}+\mathrm{H}]^{+}$.

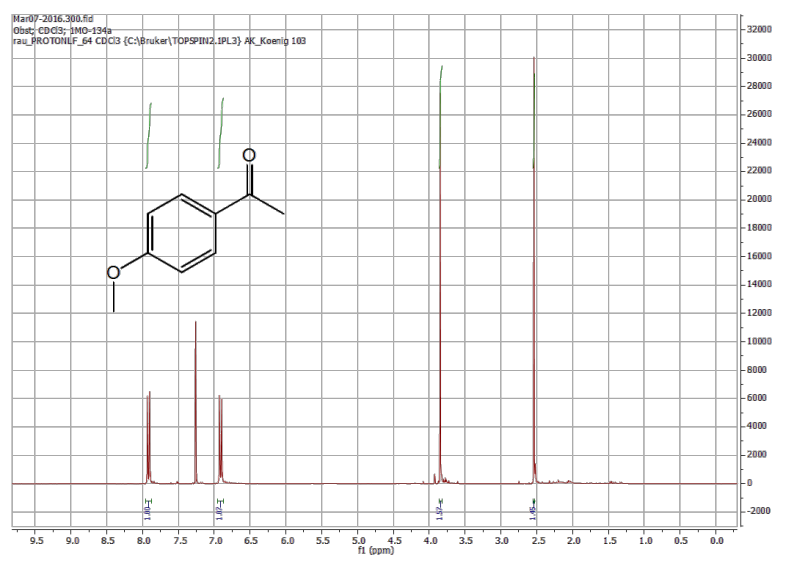

Figure 2: ${ }^{1} \mathrm{H}$ NMR (crude) of 4-methoxyacetophenone $6 \mathbf{b}$

\section{Supporting Information}

\section{Supporting Information File 1}

Video showing the rod mill apparatus and the procedure of loading and reaction.

[http://www.beilstein-journals.org/bjoc/content/ supplementary/1860-5397-12-229-S1.mp4]

\section{References}

1. James, S. L.; Adams, C. J.; Bolm, C.; Braga, D.; Collier, P.; Friščić, T.; Grepioni, F.; Harris, K. D. M.; Hyett, G.; Jones, W.; Krebs, A.; Mack, J.; Maini, L.; Orpen, A. G.; Parkin, I. P.; Shearouse, W. C.; Steed, J. W.; Waddell, D. C. Chem. Soc. Rev. 2012, 41, 413-447. doi:10.1039/C1CS15171A

2. Trotzki, R.; Hoffmann, M. M.; Ondruschka, B. Green Chem. 2008, 10, 767-772. doi:10.1039/b801661e

3. Reckenthaeler, M.; Griesbeck, A. G. Adv. Synth. Catal. 2013, 355, 2727-2744. doi:10.1002/adsc.201300751

4. Ohkubo, K.; Suga, K.; Fukuzumi, S. Chem. Commun. 2006, 2018-2020. doi:10.1039/b518127e

5. Ohkubo, K.; Hirose, K.; Fukuzumi, S. Chem. - Eur. J. 2015, 21 , 2855-2861. doi:10.1002/chem.201404810

6. Feng, W.; Wu, G.; Li, L.; Guan, N. Green Chem. 2011, 13, 3265-3272. doi:10.1039/c1gc15595d

7. Yuan, R.; Fan, S.; Zhou, H.; Ding, Z.; Lin, S.; Li, Z.; Zhang, Z.; Xu, C.; Wu, L.; Wang, X.; Fu, X. Angew. Chem., Int. Ed. 2013, 52, 1035-1039. doi:10.1002/anie.201207904

8. Lang, X.; Chen, X.; Zhao, J. Chem. Soc. Rev. 2014, 43, 473-486. doi:10.1039/C3CS60188A

9. Cibulka, R.; Vasold, R.; Koenig, B. Chem. - Eur. J. 2004, 10, 6223-6231. doi:10.1002/chem.200400232

10. Svoboda, J.; Schmaderer, H.; Koenig, B. Chem. - Eur. J. 2008, 14, 1854-1865. doi:10.1002/chem.200701319

11. Lechner, R.; Koenig, B. Synthesis 2010, 1712-1718. doi:10.1055/s-0029-1218709

12. Lechner, R.; Kuemmel, S.; Koenig, B. Photochem. Photobiol. Sci. 2010, 9, 1367-1377. doi:10.1039/c0pp00202j

13. Schmaderer, H.; Hilgers, P.; Lechner, R.; Koenig, B. Adv. Synth. Catal. 2009, 351, 163-174. doi:10.1002/adsc.200800576

14. Muehldorf, B.; Wolf, R. Chem. Commun. 2015, 51, 8425-8428. doi:10.1039/C5CC00178A

15. Metternich, J. B.; Gilmour, R. J. Am. Chem. Soc. 2015, 137, 11254-11257. doi:10.1021/jacs.5b07136

16. Metternich, J. B.; Gilmour, R. J. Am. Chem. Soc. 2016, 138, 1040-1045. doi:10.1021/jacs.5b12081

17. Larson, R. A.; Stackhouse, P. L.; Crowley, T. O. Environ. Sci. Technol. 1992, 26, 1792-1798. doi:10.1021/es00033a013

\section{License and Terms}

This is an Open Access article under the terms of the Creative Commons Attribution License (http://creativecommons.org/licenses/by/4.0), which permits unrestricted use, distribution, and reproduction in any medium, provided the original work is properly cited.

The license is subject to the Beilstein Journal of Organic Chemistry terms and conditions: (http://www.beilstein-journals.org/bjoc)

The definitive version of this article is the electronic one which can be found at: doi:10.3762/bjoc. 12.229 